Pompeu, D. - Stimmungen Lesen (resenha)

\title{
Stimmungen Lesen, ler entre a forma e a substância
}

\author{
Stimmungen Lesen - Reading between Form and Substance
}

Douglas Pompeu ${ }^{1}$

GUMBRECHT, Hans Ulrich. Stimmungen Lesen. Über eine verdeckte Wirklichkeit der Literatur. Munique, Carl Hanser Verlag 2011.

Publicado na Alemanha em 2011 pela editora Carl Hanser, o último livro do romanista Hans Ulrich Gumbrecht foi lido com certa resistência por alguns críticos e teóricos da literatura. A provocação ou o motivo das reações controversas ao livro não se encontram no conjunto de ensaios já publicados pelo autor na seção Geisteswissenschaften no Frankfurter Allgemeinen Zeitung e que recheiam a edição atual, mas sim no título e na introdução de cerca de trinta páginas, na qual o autor parte de um suposto impasse ou de um limite dos estudos literários nas últimas décadas e arrisca afirmar ter encontrado uma solução para a sensação de letargia e insegurança que toma conta da crítica e da teoria contemporânea. Uma versão da introdução de Stimmungen Lesen. Über eine verdeckte Wirklichkeit der Literatur, publicado primeiramente em alemão, apareceu em 2008 na revista americana boundary2 e foi traduzida para o português no ano seguinte na revista Índice, intitulada por uma pergunta: Ler para Stimmung? Sobre a ontologia da literatura hoje ${ }^{2}$. A suposta hesitação no título anterior entre realidade e ontologia talvez adiante a intenção do autor. Ao se referir a uma realidade encoberta da literatura, Gumbrecht arrisca anunciar uma terceira posição ontológica da literatura que não compactuaria com nenhum dos pressupostos dominantes e contraditórios, responsáveis pela estagnação da crítica hoje, a saber o Desconstrucionismo, de um lado, e os Cultural Studies, de outro. Essa terceira posição, segundo o autor, deixada de lado até o presente, ao invés de ver a literatura apenas como representação de uma realidade, ocupa-se com aquilo que estaria além da interpretação, que sobra ou resiste a ela, mas que comove o leitor corporalmente, ou como o próprio autor esclarece por meio de um verso de Toni Morrison, aquilo

\footnotetext{
${ }^{1}$ Mestre em Literatura Alemã na Faculdade de Filosofia, Letras e Ciências Humanas da USP. E-mail: glaspom@me.com

${ }^{2}$ Em inglês Reading for the Stimmung? About the Ontology of Literature Today" na seção "Interventions" da revista boundary2, volume 35, n. 3, 2008.
} 


$$
\text { Pompeu, D. - Stimmungen Lesen (resenha) }
$$

que o toca por interiormente ${ }^{3}$. Essa posição resolutiva, segundo Gumbrecht, poderia ser ilustrada por fim pela palavra alemã de difícil tradução "Stimmung".

Em um dos dez tópicos em que se divide a introdução do livro, o autor ocupa-se com as diferentes nuances da palavra alemã. Para isso, recorre a duas palavras em inglês "mood" e "climate", ambas possíveis traduções para "Stimmung". Enquanto uma refere-se a uma sensação interna e subjetiva, para a qual nenhuma descrição exata seria possível, a outra refere-se a algo objetivo que envolve indivíduos ou um grupo de pessoas e que exerce uma influência física sobre eles. Desse modo, o autor parece encontrar uma chave para a ligação imediata entre sujeito e objeto. Além disso, "Stimmung" partilha a mesma raiz de "Stimme" (voz) e do verbo "stimmen", que primeiramente está ligado ao verbo afinar, em afinar um instrumento, mas também ao estar certo de algo (na expressão “das stimmt”, por exemplo). Gumbrecht desenvolve então uma relação desses desdobramentos com o universo da música, do som e do ouvir e, em segundo momento, com o sentido de atmosfera e clima (Wetter). Ele ressalta que não ouvimos apenas por meio de nosso ouvido interno e externo, mas que ouvir é uma forma de comportamento complexa e corporal que exerce um papel muito importante para nossa percepção táctil e física do mundo. Justamente por isso, comenta o autor, não é difícil encontrar referências à música e ao clima em textos literários que procuram presencializar o passado (vergegenwärtigen), ou que se referem auto-reflexivamente a uma Stimmung. É nesse ponto que reside a razão do autor em acreditar que ler orientado por uma Stimmung pode abrir uma nova perspectiva dentro da ontologia da literatura: pois na oposição entre Desconstrução e os Estudos Culturais toda possível relação com a realidade não-linguística é pensada pelo paradigma da representação. Segundo essa orientação, textos representam,ao passo que leituras orientadas pela Stimmung se ocupariam com a dimensão textual da forma (principalmente o som, através de aliterações e assonâncias, por exemplo, na leitura de um texto) que envolvem nosso corpo enquanto realidade física potencial e que podem provocar um sentimento interno, sem que seja necessário recorrer ao nível da interpretação.

Diante de Stimmungen Lesen, é quase inevitável pensar no famoso ensaio de Susan SonTAG Against Interpretation (1964) - aliás sequer mencionado pelo autor -, na crise da representação levantada pelas teses de Michel Foucault ou ainda em Real Presences (1991) de George STEINER. No entanto, Gumbrecht procura se instrumentalizar filosoficamente por meio do diálogo com filósofos como Martin Heidegger, ao defender uma relação com o mundo não-interpretativa, corporal e pré-hermenêutica e diferenciar uma sociedade de sentido de uma sociedade de presença.

\footnotetext{
${ }^{3}$ No original: "touched like from inside".
} 


$$
\text { Pompeu, D. - Stimmungen Lesen (resenha) }
$$

Na verdade, para quem acompanhou as mais recentes publicações do romanista, a reação provocada pelo seu último livro não é motivo de surpresa. Desde a publicação de Production of Presence (2004), livro importante para entender os movimentos de Gumbrecht, seus esforços sobre a questão da presença e o próprio uso que o autor faz do conceito de "Stimmung", estabeleceu-se um malestar $^{4}$ em relação à sua tentativa de delinear um desvio para as posições ontológicas dominantes nos estudos literários que, segundo o autor, são responsáveis por delimitar qualquer tipo de referência linguística ao mundo fora da linguagem como impossíveis ou não-demonstráveis. Pois para Gumbrecht, se a Desconstrução, apesar das intensivas pretensões de inovação, se inscreve filosoficamente sem resistência na tradição do linguistic turn, por não conseguir ir além da linguagem, os Cultural Studies, ao contrário do anterior, não levantam nenhuma dúvida sobre a capacidade da literatura fazer referência ao mundo real, o que produz de um lado um otimismo empírico e, de outro, o que o autor chama de "descuido epistemológico", marcantes em uma sociedade pautada inteiramente pelo sentido.

Stimmungen Lesen pode ser lido como uma continuidade das reflexões do autor sobre o efeito de presença em nossa cultura, como uma tentativa de apresentar as bases de uma sociedade de presença por vir. O próprio autor o assume, um ano antes da publicação do livro, em seminário na Casa de Rui Barbosa. No seminário o romanista afirma que, como consequência do processo da modernidade, em nossa relação consciente com as coisas do mundo, a interpretação prevalece arbitrariamente em primeiro plano na atribuição de sentido; no entanto, esse nosso hábito involuntário ou intuitivo de atribuir sentido às coisas estaria, desde sempre e ao mesmo tempo, em relação constante com nossos corpos. Isso é o que poderia ser chamado de presença: uma relação física, corporal e imediata entre as coisas e os sujeitos. E a chave para essa relação seria a transferência de uma presença substancial do passado, uma Stimmung transmitida pelo objeto artístico. Já que, ao envolver uma camada física de fenômenos, Stimmungen pertenceriam a uma parte presencial da existência e, na sua forma de articulação, se inscreveriam no nível da experiência estética. Nesse sentido, Stimmung é aquilo que, em um texto, sem ter nada a ver com interpretação e sem qualquer esforço para atribuir sentido, nos liga com seu tempo (sempre passado) e o torna vivo e vivenciável no agora.

A publicação em questão procura justamente transmitir essa relação presente e estética com o mundo por meio da literatura e de outros artefatos como a pintura e a música. Sua justificativa é que uma nostalgia e uma necessidade por Stimmung vem crescendo nas últimas décadas, sobretudo

\footnotetext{
${ }^{4}$ Inclusive no Brasil: em 19 de fevereiro de 2011, o caderno Prosa e Verso do jornal O Globo publicou resenha de Andrea Daher sobre Production of Presence que rendeu um debate com réplica e tréplica entre ela e Gumbrecht.
} 


$$
\text { Pompeu, D. - Stimmungen Lesen (resenha) }
$$

entre a geração a que pertence o autor, os "mais velhos", testemunhas de vida que segue um rumo ordinário sem a capacidade de envolver e afetar nossos corpos, como se estivéssemos agora sedentos por presença ou como se essa estagnação a que chegou a modernidade esteja nos distanciando da vida condensada nesses objetos. Os problemas surgem quando o autor reflete sobre um possível método para a leitura orientada pela Stimmung. É possível pensar em um modo científico para tratá-la ou compreendê-la? De fato, quando se fala em Stimmung adentra-se em um terreno obscuro e incerto, pois trata-se de algo individual e subjetivo. Para Grumbrecht, mesmo que cada Stimmung seja histórica e culturalmente única, ler orientado por uma Stimmung não é o mesmo que analisar ou reconstruir uma gênese cultural e histórica. Cético em relação a possíveis teorias gerais ou métodos capazes de esclarecer e lidar com Stimmungen, o romanista aposta suas fichas no pensamento contra-intuitivo. Como afirma o autor, um pensamento que não receia divergir das normas dominantes da racionalidade e da lógica tem muito a ganhar ao se valer de intuições, pois o que primeiro chama a atenção em uma leitura orientada pela Stimmung é uma fascinação ou irritação provocadas por uma única palavra ou detalhes, o fragmento de um som ou um ritmo. Dessa maneira, seria possível ao texto crítico se aproximar, convergir com o seu objeto ao invés de se distanciar cada vez mais dele. O modelo dessa crítica corresponderia, para o autor, ao conceito de "ensaio" discutido por Georg Lukács em Die Seele und die Formen. Por meio dos ensaios seria possível acessar sem mediações o vivenciado ou a vida [“das Erleben”] na leitura de um texto literário.

Os ensaios que seguem a introdução do livro parecem querer ilustrar uma tentativa nesse sentido. Divididos em "momentos" e "situações", os textos reunidos por Gumbrecht são considerados pelo próprio como estudos imanentes e tratam da poesia medieval de Walther von der Vogelweide, da prosa de Pícaro, Diderot, María de Zayas, Machado de Assis e Thomas Mann, passando pelos sonetos de Shakespeare, pela pintura de Casper David Friedrich e pela canção "Me and Bobby MacGee" de Janis Joplin. No caso das "situações", o autor procura esclarecer, por meio de uma leitura orientada pela Stimmung, o Surrealismo dos anos 20 e a Desconstrução de Jacques Derrida e Paul de Man. Obviamente, diante desse número variado de obras e gêneros distintos, cada qual com sua poética e seu contexto de produção, não se pode esperar que uma leitura orientada por uma Stimmung constitua um fenômeno uniforme. Além disso, é de fato espantoso que a afinidade musical com o conceito de Stimmung, a materialidade ou esse fenômeno físico que atinge o leitor através da prosódia, seja tão pouco explorada nos ensaios, principalmente quando tratam da leitura de poemas. Ao se ocupar com os poemas de Vogelweide, o autor focaliza, por exemplo, a frágil Stimmung de uma irritabilidade do "eu" produzido pelo plano de fundo de seu tempo; no caso dos 


$$
\text { Pompeu, D. - Stimmungen Lesen (resenha) }
$$

sonetos shakespearianos, uma Stimmung enquanto "unidade complexa de sons": ambos, é preciso aceitar, muito distantes de algo como uma Stimmung própria da lírica. Já ao tratar da prosa de Pícaro, o foco recai sobre um "sentimento de vida"; sobre Diderot fala-se de Stimmung como um tempo e uma atmosfera, um clima; em Morte em Veneza, de Thomas Mann, é a convergência entre estados de humor e situações climáticas que é direcionada pela Stimmung. Na verdade, as leituras orientadas pela Stimmung são sintomaticamente muito mais esclarecedoras no caso das obras menos conhecidas da literatura mundial como a de María de Zayas e de Machado de Assis. Como o autor defende na introdução, nenhuma linha histórica é mencionada ou evidenciada, mas, em consequência disso, pode se acusar que os objetos acabam demasiado dispersos e o conceito de Stimmung muito aberto e sem contorno.

Em todo caso, se o que a introdução do livro promete não é totalmente verificável nos ensaios que a seguem, isso talvez se deva ao fato de que, em última estância, defender um tipo de abordagem da literatura que seja capaz de tornar espaços e tempos experienciáveis corporalmente ainda efetue-se por meio de um gesto crítico constituído menos pelo pensamento contra-intuitivo do que por meio do pensamento analítico. Diante dos ensaios, alguns críticos chegaram a sugerir que o recurso à Stimmung possibilitaria, pelo contrário e de modo ainda mais eficaz, curtos-circuitos hermenêuticos, nos quais o leitor pudesse reconhecer nos detalhes de uma obra o espírito de um tempo, como já propuseram Friedrich Schlegel e Leopold Ranke. Outros ainda: se textos literários atingem o leitor imediatamente por meio de sua camada prosódica, não seria, no entanto, ser possível chegar a uma Stimmung apenas depois da semantização? Com isso não estaríamos pisando novamente na dimensão dos signos? Contudo, se todo o esforço do autor em querer descolar o centro das discussões da cena atual para o problema aristotélico do símbolo e para a diferença entre substância e forma ainda carece de uma base sólida e convincente para seus críticos, seu maior mérito até agora reside, a meu ver, no modo provocativo como o autor procura, apesar de melancólico, tirar o pó que vem se acumulando nos estudos literários hodiernos. O que pode, quem sabe, por meio de uma irritação - valendo-se aqui das diferentes nuances semânticas da palavra providenciar uma dinâmica e um debate menos letárgicos ao campo. 